\title{
Directly Measured and Self-Reported Physical Activity in a Sample of Finnish Secondary School Students
}

\author{
Arto Gråstén $^{1 *}$, Anthony Watt ${ }^{2}$, Timo Jaakkola $^{1}$, Jarmo Liukkonen ${ }^{1}$ \\ ${ }^{1}$ Department of Sport Sciences, University of Jyvaskyla, Jyvaskyla, Finland \\ ${ }^{2}$ School of Education, Victoria University, Melbourne, Australia

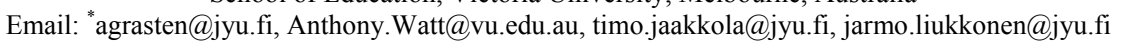

Received May $28^{\text {th }}, 2012$; revised June $27^{\text {th }}, 2012$; accepted July $11^{\text {th }}, 2012$

\begin{abstract}
Background: Previous studies based on self-reports show that a majority of children and adolescents in Western countries fail to achieve the recommendation of 60 minutes moderate to vigorous physical activity (PA) on a daily basis. The specific aim of the study was to analyze the relationship between directly measured and self-reported PA in a cross-sectional sample of Finnish secondary school students. Moreover, how large proportion of adolescents accumulate at least 60 minutes of moderate to vigorous PA on a daily basis using self-reports and direct measure scores. Methods: Participants were recruited from a secondary school located in Northeast Finland. The sample comprised 96 students ( 58 girls, 38 boys) aged between 12 - to 16 -years $(\mathrm{M}=15.03, \mathrm{SD}=.94)$. Students' directly measured PA was collected using accelerometers over a seven-day period. The self-reported PA data was gathered during the school's allotted 90-minute lessons. Results: Results indicated that girls and boys were similarly physically active, based PA measured using both accelerometers and questionnaires. Grade 7 students were physically more active than Grade 9 students when PA was assessed using self-reports but no significant difference was found when direct measure scores were used. Self-reported PA emerged as the significant positive predictor for students' directly measured PA within Grade $8(p<.001)$, and Grade 9 students $(p<.01)$. The results highlighted that only $10 \%$ of adolescents met the recommendation of 60 minutes moderate to vigorous PA daily, when PA was measured using self-reports. On the contrary, a portion of $85 \%$ of students met the recommendation, when direct measure scores were used. Conclusion: Because the current and previous findings indicated substantial differences in the assessments results for similarly aged samples, continuing studies using directly assessed techniques are required to gain detailed information concerning the PA behavior of Finnish children and adolescents.
\end{abstract}

Keywords: Physical Activity; Accelerometers; Self-Reports; Secondary School

\section{Introduction}

Recent evidence from the World Health Organization (2012) reinforces the strong link between physical activity (PA) and continuing positive benefits to health, well-being and weight control. According to the recommendations of health experts, all secondary school-aged students should be physically active for at least 60 minutes on a daily basis (World Health Organization, 2012). A review of recent nationally representative studies based on self-reported PA (Finnish Board of Education, 2011; Ministry of Social Affairs and Health, 2007; National Institute for Health and Welfare, 2010), however, showed that only $10 \%-40 \%$ of Finnish adolescents achieve these recommended levels. Similarly, self-report data drawn from large sample studies in the US indicated that the minority of adolescents (37\% - 41\%) had five or more sessions of moderate to vigorous PA (MVPA) per week (Gordon-Larsen, Nelson, \& Popkin, 2004). In addition, when the activity was assessed directly using accelerometers, Troiano et al. (2008) reported that within a large sample of the US population, only $8 \%$ of adolescents obtained the recommended 60 minutes of PA on a daily basis. The numbers of physically active adolescents could be considered to be relatively high when PA was measured using self-

\footnotetext{
"Corresponding author.
}

reports. The gap between self-reports and directly measured scores makes it difficult to estimate the quantity of physically active adolescents, and furthermore to support policy and decisionmaking in the domain of children's and young people's health and well-being. The current study compared direct technique (accelerometer) to a more traditional subjective method (questionnaire) for the assessment of PA in a cross-sectional sample of Finnish secondary school students.

During adolescence, the opportunities for PA consist mainly of commuting to school, school physical education (PE), PA during recess and leisure time, participation in sports, and unorganized PA. A limitation highlighted in relation to the PA measurement techniques used with children and youth is that most methods are unable to evaluate multiple dimensions of PA at the same time (e.g., frequency, type, intensity, and duration) (Dale, Welk, \& Mattews, 2002). This typically necessitates that research dependent on highly accurate assessment of PA would requires the use of multiple approaches.

A range of measurement techniques are available for assessing PA in children and adolescents. Measures of PA, such as direct observation (McKenzie, 2002) indirect calorimeter (Sirard \& Pate, 2001), doubly labeled water (Arvidsson, Slinde, \& Hulthen, 2005), pedometers (Tudor-Locke et al., 2002), accelerometers (Rowlands, 2007), heart rate monitors (Eston, Rowlands, \& Ingledew, 1998) and multichannel activity monitor (Trost, McIver, 
\& Pate, 2005) are considered as objectively or directly measured because the data being collected do not need to be cognitively and perceptually processed by the participants (Marshall \& Welk, 2008). Limitations of direct measures also exist such as higher costs compared to self-report and the requirement for devices to be worn consistently and in the prescribed method to gather reliable data (Bates, 2006). PA may also be viewed as a latent, not directly observable, and time categorizable according to activity type and intensity, which can vary substantially over short periods of time (Corder et al., 2008). Direct measures can provide important insights into the true activity levels of adolescents (Bates, 2006) and the main techniques (e.g., accelerometers, multichannel activity monitors, heart rate monitors) have been shown to provide more accurate measures of PA than self-reported methods in children and adolescents (Bates, 2006; de Vries et al., 2006; Trost, 2000).

Self-reported PA measures have been used widely in many countries to assess overall PA, including Finland for the purposes of economical and practical expediency. However, previous findings have shown that children and adolescents are less able than adults to recall their PA levels, indicating that questionnaires provide a restricted measure of PA in children and adolescents (Marshall \& Welk, 2008). Additionally, selfreport measures, such as diaries (Rodriguez et al., 2002), logs (Welk et al., 2007), interviews (Welk et al., 2007), and questionnaires (Arvidsson, Slinde, \& Hulthen, 2005) require a certain level of cognitive and perceptual processing by the participants to generate the data (Marshall \& Welk, 2008). During adolescence, individuals become more capable of abstract, multidimensional, planned and hypothetical thinking on tasks in which they need to utilize basic cognitive mechanisms, such as shortor long-term memory (e.g., when recalling their PA levels) (Keating, 2004). Generally, self-assessment methods are reliable and valid, relatively simple and inexpensive to administer, and appropriate for use in population studies (Bates, 2006). Despite the variety of measurement methods, it is important to recognize that measurements of PA provide only estimates of actual behavior irrespective of the method being used (Marshall \& Welk, 2008).

In previous studies, the correlation between self-reported and directly measured PA has varied as a function of the method used. In a study involving a sample of 115 American rural girls and boys with a mean age of 13.8 years, the correlation between self-reported PA and accelerometer-based PA was low $(\mathrm{r}=.39, p<.01)$ (Moore, Maloney, \& Yin, 2007). Prochaska, Sallis, and Long (2001) also reported that for a US sample of 250 boys and girls with a mean age of 15 years, the self-reported measure had low correlation with the accelerometer data $(\mathrm{r}=.40$, $p<.001$ ). According to the findings of Trost et al. (2002), for overall PA, the magnitudes of the gender differences in PA were small when measured directly by accelerometers. Shiely and MacDonncha (2009) found that, when PA was measured using a self-report questionnaire, more than $11 \%$ of 28 Irish adolescents met the international moderate intensity PA guidelines for adolescents, whereas, no adolescent met the international guidelines on sustained vigorous physical activity using heart rate monitors. The possible reason for differences is that the various techniques are based on different procedures, they provide raw data that are not directly comparable (Dale, Welk, $\&$ Mattews, 2002). Trost, McIver and Pate (2005) suggested that at least a seven-day monitoring protocol provides reliable estimates of usual PA behavior in children and adolescents. The current review of PA studies involving children and adolescents highlighted a consistent theme, whereby, researchers were typically proposing that to advance knowledge on PA in children and youth, it is important to obtain valid and reliable measurements of typical behavior (e.g., Bates, 2006; Marshall \& Welk, 2008; Shiely \& MacDonncha, 2009).

Although a large number of Finnish (Finnish Board of Education, 2011; Ministry of Social Affairs and Health, 2007; National Institute for Health and Welfare, 2010; Yli-Piipari, 2011), and international studies (Moore, Maloney, \& Yin, 2007; Shiely \& MacDonncha, 2009; Slootmaker et al., 2012; World Health Organization, 2004, 2008) highlight the increasing numbers of physically inactive children and adolescents, many of these findings are derived from self-report data. Furthermore, there is a lack of studies analyzing predictive relationships between selfreported and directly measured PA in children and adolescents. These types of comparisons would assist in determining if generally used self-reported PA instruments are sufficiently accurate to support policy and decision-making in the domain of children's and young people's health and well-being. Given the complexity of the construct and the variety of applications for measures of PA, continued methodological research is needed (Troiano, 2009).

The specific aim of the study was to examine if directly measured and self-reported PA differ by gender or grade. On basis of the theoretical framework (Marshall \& Welk, 2008), it was expected that boys and Grade 7 students would score higher. A second aim was to analyze the predictive strength of selfreports on direct PA in a cross-sectional sample of Finnish secondary school students. In line with earlier studies (Moore, Maloney, \& Yin, 2007), it was expected that self-reports would moderately predict directly measure scores. The final aim was to investigate the proportion of adolescents accumulating at least 60 minutes of moderate to vigorous physical activity (MVPA) on a daily basis as assessed by self-report and directly measured scores. In line with previous findings (Shiely \& MacDonncha, 2009; Slootmaker et al., 2012), it was proposed that directly measured PA would reveal lower numbers of adolescents meeting the recommendation of daily PA levels than self-reported PA.

\section{Methods}

\section{Participants}

Participants were recruited from a secondary school located in Northeast Finland through direct contact with the school principal. All students in each PE class were invited to participate. Participation in this study was voluntary and no extra credit was awarded for participation. The sample comprised 96 adolescents (58 girls, 38 boys) aged between 12- to 16-years $(\mathrm{M}=15.03, \mathrm{SD}=.94)$. Permission to conduct the study was obtained from the Ethical Committee of the University of Jyvaskyla. Written, informed consent was obtained from each student and their parent or legal guardian after they were given, in writing, a full explanation of the aims of the study, possible hazards, discomfort, and inconvenience.

\section{Instruments}

\section{Directly Measured PA}

Accelerometers (Polar Active) were used for the direct assess- 
ment of students' PA. The monitors were light, small, and worn on the wrist. Daily activity was detected automatically, including intensity (MVPA) and duration (minutes). The total minutes represented adolescents' MVPA. In the first validation study (Virtanen, 2011), conducted for a sample of Finnish 6 - 15 year old children and adolescents $(n=20)$, Polar Active's assessment in METs for playing games, walking and running had a high correlation to METs assessed using indirect calorimetry ( $\mathrm{r}$ $=.91)$, whereas the correlation was low for sitting activities ( $\mathrm{r}$ $=.31$ ). In another validation study (Virtanen, 2011), the correlation between Polar Active and indirect calorimetry $(r=.86)$ was similar to the correlation between Actigraph accelerometers and indirect calorimetry $(r=.84)$ in seven different activities (sitting quietly, seated playing a video game, a standing warm-up, walking, jumping rope, video-led kickboxing, running for a total of $30 \mathrm{~min}$ ) in a sample of 23 Finnish $11-17$ year-old children and youth.

\section{Self-Reported PA}

Self-reported PA was assessed using the Health Behavior in School-aged Children Research Protocol (Currie et al., 2002) which incorporated a modified version of the Moderate to Vigorous Physical Activity (MVPA) measure (Prochaska, Sallis, \& Long, 2001). The introduction preceding the items was: "In the next two questions physical activity means all activities which raises your heart rates or momentarily get you out of breath for example in doing exercise, playing with your friends, going to school, or in school physical education. Sport also includes for example jogging, intensive walking, roller skating, cycling, dancing, skating, skiing, soccer, basketball and baseball." The items required students to summarize their time spent in physical activity each day in the following way: 1) "When you think about your typical week, on how many days you are physically active for a total of at least 60 minutes per day?" and 2) "Over the past 7 days, on how many days were you physically active for a total of at least 60 minutes per day?" Both items used an eight-point response scale ( 0 to 7 days in a week). The mean of the two items was calculated and used as the adolescents' PA score. Prochaska, Sallis, and Long (2001) reported that for a sample of 138 US children and adolescents with a mean age of 12.1 years, the moderate to vigorous PA items were reliable $(\mathrm{ICC}=.77)$ and correlated moderately $(\mathrm{r}=.40)$ with accelerometer data in a study based on a five-day data collection period.

\section{Design of the Study}

The current cross-sectional data was compiled as part of a research project for promoting PA and health among children and youth. Self-report PA data was collected by the researchers during the school's allotted 90-minute lessons in April 2011. The participants had the procedures explained to them verbally, including a brief overview of possible physical discomfort that could be caused from wearing an accelerometer. The students were told that their involvement was voluntary and to ask for help if confused concerning the instructions, or if they required clarification of a particular item. To address the possibility of students' giving socially desirable responses, students were encouraged to answer honestly and were assured that their responses were confidential. Directly measured PA data was obtained during a seven-day period. The instructions for the use of the accelerometers were given by the researchers during the school PE lessons. Students provided demographic information associated with age, gender, height, and weight. The participants were asked to wear the accelerometers for 24 hours a day over a seven-day period. The monitors were collected by the PE teachers, and the data was downloaded to a computer by the researchers.

\section{Statistical analyses}

Prior to statistical analyses, normality, missing values, and outliers of the data were examined. The graphics and values of skewness (-.168 to .571$)$ indicated that the data was within accepted limits to be considered normally distributed. The outliers were analyzed using standardized values $( \pm 3.29)$, and Mahalanobis distance $(p<.001)$ (Tabachnick \& Fidell, 2007). One unit containing missing value and three outliers in directly measured PA were removed. No further modifications were required. The scores for both directly measured and self-reported PA were summarized using descriptive statistics. Pearson's correlation coefficients were examined to allow comparison with previous studies. Gender and grade differences were analyzed using MANOVA and Tukey's HSD-test. Prior to the MANOVA, the homogeneity of variance-covariance matrices was examined using Box's M test which revealed no violation either in self-reported $(\mathrm{F}=.790, p>.05)$ or directly measured data $(\mathrm{F}=.135, p>.05)$. Because of the nature of this study, general linear model of regression analysis was used to investigate the predictive strength of self-reported PA on directly measured PA (Yang \& Miller, 2008). The distributions of regression residuals were analyzed using the Kolmogorov-Smirnov test which showed that the studentized residuals distributed normally within all grades $(p>.05)$. Statistical analyses were conducted using SPSS 19.0 software.

\section{Results}

\section{Descriptive Statistics, Differences, and Correlation Coefficients}

Descriptive statistics are presented in Table 1. The MANOVA yielded a significant main effect for grade in directly measured PA (Wilks's $\Lambda=.89, \mathrm{~F}(1,96)=4.32, p<.05 ; \eta p 2=.04)$ and self-reported PA (Wilks's $\Lambda=.89, \mathrm{~F}(1,96)=10.86, p<.001$; $\eta p 2=.11)$. Tukey's HSD-test revealed that Grade 7 students were significantly more physically active than Grade 9 students when PA was measured using self-reports $(p<.01)$. No further differences were found. Additionally, the Pearson's correlation coefficient between self-reported and directly measured PA scores was moderate in Grade 8 students $(\mathrm{r}=.66, p<.001)$, whereas the correlations were low in both Grade $9(\mathrm{r}=.44, p$ $<.01)$, and Grade 7 students $(\mathrm{r}=.32, p>.05)$.

\section{Linear Regression Analysis}

The results of the linear regression analyses conducted for each grade level indicated (Table 2) that self-reported PA emerged as the significant positive predictor for students' directly measured PA within Grade 8 students $(p<.001)$, and Grade 9 students $(p<.01)$, accounting for $41.6 \%$ and $17.3 \%$ of variance. Self-reported PA was not a significant contributor for Grade 7 students' direct PA.

\section{Achievement of the Recommendation of Daily PA}

Results for self-reported PA indicated that only $11 \%$ of adolescents met the requirement for minimum 60 minutes of MVPA 
Table 1.

Descriptive statistics of directly measured and self-reported PA.

\begin{tabular}{|c|c|c|c|c|c|c|c|}
\hline \multirow{10}{*}{$\begin{array}{c}\text { Direct PA } \\
\text { (minutes) }\end{array}$} & \multirow{4}{*}{ Grade 7} & \multirow[b]{2}{*}{ Girls } & \multirow{2}{*}{$\begin{array}{l}\mathbf{N} \\
19\end{array}$} & \multirow{2}{*}{$\frac{\text { Min }}{63.57}$} & \multirow{2}{*}{$\begin{array}{c}\text { Max } \\
223.57\end{array}$} & \multirow{2}{*}{$\frac{\mathbf{M}}{119.90}$} & \multirow{2}{*}{$\frac{\text { SD }}{34.08}$} \\
\hline & & & & & & & \\
\hline & & Boys & 6 & 74.43 & 150.14 & 113.50 & 27.58 \\
\hline & & Total & 25 & 63.57 & 223.57 & 118.36 & 32.21 \\
\hline & & Girls & 16 & 38.00 & 169.14 & 101.48 & 44.17 \\
\hline & Grade 8 & Boys & 13 & 28.20 & 206.57 & 108.88 & 56.25 \\
\hline & & Total & 29 & 28.20 & 206.57 & 104.80 & 49.14 \\
\hline & & Girls & 23 & 36.57 & 216.43 & 95.68 & 51.67 \\
\hline & Grade 9 & Boys & 19 & 55.14 & 162.12 & 94.90 & 35.66 \\
\hline & & Total & 42 & 36.57 & 216.43 & 95.33 & 44.62 \\
\hline \multirow{9}{*}{$\begin{array}{l}\text { Self-reported } \\
\text { PA } \\
\text { (days/week) }\end{array}$} & & Girls & 19 & 3 & 7 & 5.39 & 1.14 \\
\hline & Grade 7 & Boys & 6 & 4 & 7 & 5.50 & 1.27 \\
\hline & & Total & 25 & 3 & 7 & 5.42 & 1.14 \\
\hline & & Girls & 16 & 1 & 7 & 4.38 & 1.79 \\
\hline & Grade 8 & Boys & 13 & 2 & 7 & 4.69 & 1.81 \\
\hline & & Total & 29 & 1 & 7 & 4.52 & 1.78 \\
\hline & & Girls & 23 & 2 & 7 & 4.00 & 1.39 \\
\hline & Grade 9 & Boys & 19 & 1 & 7 & 4.29 & 1.83 \\
\hline & & Total & 42 & 1 & 7 & 4.13 & 1.59 \\
\hline
\end{tabular}

Table 2.

Results of regression analysis on students' directly measured PA ( $\mathrm{N}=$ 96).

\begin{tabular}{llllc}
\hline & & $\boldsymbol{\beta}$ & $\mathbf{R}^{2}$ & t-value \\
\cline { 2 - 5 } Self-reported PA & Grade 7 & .320 & .064 & 1.62 \\
& Grade 8 & .661 & .416 & $4.57^{* * *}$ \\
& Grade 9 & .440 & .173 & $3.10^{* *}$ \\
\hline
\end{tabular}

${ }^{* *} p<.01,{ }^{* * *} p<.001$

per day. In contrast, $85 \%$ met the recommendation based on direct measure scores. Self-report data indicated that a minimally larger portion of Grade 8 students $(13.1 \%)$ achieved the recommendation than either Grade $7(12.0 \%)$ or 9 students $(9.3 \%)$. Conversely, a higher percentage of Grade 7 students $(92.0 \%)$ met the requirement of 60 minutes daily PA when assessed by direct measures than either Grade $8(76.3 \%)$ or $9(85.2 \%)$ students.

\section{Discussion}

Currently, no studies that incorporate both direct and selfreported measures of PA with samples of Finnish adolescents have been undertaken. The current study revealed that girls and boys were similarly physically active, based on PA measured using both accelerometers and questionnaires. Results also indicated that Grade 7 students were physically more active than Grade 9 students when PA was assessed using self-reports but no significant difference was found when direct measure scores were used. In addition, the associations between self-report and accelerometer scores were stronger for Grade 8 and 9 students than those in Grade 7. Unexpectedly, a majority of the students achieved 60 minutes of MVPA per day when PA was measured directly. In turn, self-reports revealed a smaller portion of students who met the recommendation.

The results of current study revealed that no significant gender differences were found for either self-reported or directly measured PA. This unexpected finding was not in line with previous research that showed boys were physically more ac- tive than girls based on both self-reports (Duncan et al., 2004; Finnish Board of Education, 2011; Yli-Piipari, 2011; World Health Organization, 2004; 2008) and direct measure scores (Sherar et al., 2007; Trost et al., 2002). The key strength of the current study was that both direct measures and self-reports were used, compared to the preceding national and international results. The present data was collected in a relatively small town, where walking, biking, and snow based activities are common, and local community and school facilities, including sport and exercise settings, parks, trails, and pathways may promote both girls and boys to be more physically active (Sallis et al., 2006). Many earlier studies were conducted in bigger cities where opportunities for PA are a lesser focus of the community structure. The school-based and environmental possibilities for PA could be considered to be very good for the current sample constituting a possible reason for the difference between present and previous findings. Additionally, the most recent PA study by the Finnish Board of Education (2011) found that the difference between Grade 9 girls' and boys' participation in organized and non-structured sport during leisure time narrowed over the time period of 2003-2010. Similarly, Sherar et al. (2007) reported that gender differences in PA decline across adolescence, because as children mature they tend to lower their engagement in PA. Girls reach biological maturity earlier than boys, and therefore the gender differences in PA observed early in adolescence are reduced as boys attain biological maturity. Overall, the patterns of the current and several previous PA assessments (e.g., Sherar et al., 2007; Thompson et al., 2003) indicated a trend in which the gender differences in overall PA disappeared or were consistently smaller during this age period. However, Sherar et al. (2007) concluded that to fully understand gender disparities in PA, consideration must be given to the confounding effects of physical development.

The present results showed that Grade 7 students were physically more active than Grade 9 students when PA was assessed using self-reports. This pattern was in line with earlier studies which indicated that PA declines over the secondary school years (Corbin et al., 2004; World Health Organization, 2004; 
2008; Yli-Piipari, 2011). In contrast, a significant grade difference was not found when direct measure scores were examined. Sherar et al. (2007) reported that the age-related decline in objective PA has been shown to be associated with early puberty rather than late biological maturity. The present sample comprised students aged between 12- to 16-years, therefore, some of the participants were likely prepubertal. When students reach puberty within the secondary school years, they may develop new interests and pursuits. Many of these changes, getting a motorbike licence or starting to date, for example, reduce the time available for PA. This pattern has also been observed in other adolescent samples (Allison et al., 2007). Many investigators have advocated (e.g., Bates, 2006; de Vries et al., 2006; Trost, 2000; Sherar et al., 2007) that direct measures provide more accurate measures of PA than self-reported methods in children and adolescents. Overall, the results did not fully support the expectation for grade differences. Therefore, the use of self-report measures requires careful scrutiny by researchers when used to observe age-related decline in PA, particularly secondary school students.

The results of the current study highlighted a trend in which the prediction of adolescents' directly measured PA by selfreported PA scores strengthened non-linearly across the secondary school years, whereby, the shared variance was greater at Grade 8 than either Grade 7 or Grade 9. This was the first attempt to examine the predictive relationship between self-reported and directly measured PA within Finnish secondary school students. An additional strength of the current study was that the direct data was collected for 24 hours per day over a sevenday period. Trost et al. (2000) recommended that at least a seven-day monitoring protocol is needed in order to provide reliable estimates of the usual PA behavior of children and adolescents. Adolescents may purposely under-report or overreport health and well-being behaviors including PA, because they believe engaging in these behaviors is socially undesirable or desirable (Brener, Billy, \& Grady, 2003). Taken together, the results of this study indicated that Grade 8 and 9 students managed to self-report their daily PA with a higher level of association to their directly measured PA than the Grade 7 students. Based on the current and previous findings (Prochaska, Sallis, \& Long, 2001; Shephard, 2003), researchers need to be cautious when determining actual PA by self-report with adolescent samples because the scores may only provide basic estimates of the actual behavior irrespective of the method used (Marshall \& Welk, 2008).

A larger portion of the current student sample met the recommendation of 60 minutes MVPA per day (World Health Organization, 2012) on the basis of their directly measured PA results than in relation to their self-reported PA. Only $11 \%$ of these adolescents met the daily recommendation of 60 minutes MVPA as assessed by the self-report measure. This result was consistent with the findings of the Finnish Board of Education's Physical Education Evaluation (2011) but not with other nationally representative studies (Ministry of Social Affairs and Health, 2007; National Institute for Health and Welfare, 2010). These studies reported that approximately $40 \%$ of Finnish adolescents achieve the recommendation by self-reported methods. The present study also revealed that $85 \%$ of students met the recommendation when direct measure scores were used. This finding is in contrast to previous research (Shiely, \& MacDonncha, 2009; Slootmaker et al., 2012), that reported that objectively measured PA determined smaller percentages of adoles- cents that meet the recommendation of daily PA. No previous studies incorporating directly measured methods are available in the samples of Finnish children or adolescents. When compared to the sample of US adolescents (Troiano et al., 2008), in which only $8 \%$ of adolescents met the recommendation of MVPA daily by direct measures, the percentage of physically active Finnish adolescents could be considered to be relatively high. Similarly, in a large European study (involving 2185 children and adolescents in Denmark, Portugal, Estonia, and Norway), the majority of boys (82\%) and girls (62\%) at age 15 achieved the current recommendation of PA, when PA was measured using accelerometers worn on the hip over a sevenday period (Riddoch et al., 2004). Possible reasons for differences between US and European studies may be due to cultural influences or the duration of the monitoring period. The US study included all ethnic groups, while ethnic differences have been observed in PA behavior (Biddle, Gorely, \& Stensel, 2004; Brodersen et al., 2007). The participants for present analysis were drawn from a native population of Finland. Furthermore, the US data was collected from participants who provided either one or four days of accelerometer data, whereas a sevenday monitoring was used in the present study. Because the current and previous findings indicated substantial differences in the assessments results for similarly aged samples, continuing studies using directly assessed techniques are required to gain detailed information concerning the PA behavior of Finnish children and adolescents. This will extend the limited resource of directly measured PA data gathered from research involving school-aged students. Furthermore, no clear reasons for the large differences observed between the present accelerometer and questionnaire scores have as yet been fully determined.

A key limitation of this study is related to the techniques used for PA assessment. Dale, Welk and Mattews (2002) asserted that any one technique may not detect the full range of dimensions of PA such as frequency, type, intensity or duration. The accelerometer intensity levels selected may be a reason why a larger portion of students met the recommendation of 60 minutes PA per day in the current study. The manufacturer's level for moderate PA was 3.5 MET (e.g., walking at $5.6 \mathrm{kph}$ ) whereas in a study conducted with 8 - 18 year old American children and youth (Harrell et al., 2005) using indirect calorimetry, a level of 3.8 MET was considered to represent moderate PA. Furthermore, the current cross-sectional sample of 96 students was relatively small due the available economic resources. Therefore, conclusions regarding national trends are restricted based on these findings without additional information.

In future studies, the main focus should be towards the continuing assessment of representative samples of children and adolescents of different ages using direct techniques. Additionally, longitudinal data collection incorporating both self-report and objective measures could benefit the continuing investigation of children's and adolescents' PA in PE and leisure time. Following the suggestion of Bates (2006), self-report and objective measures should be used in combination to optimize and enrich the quality of the data collected from respondents in daily PA. This information could be utilized in various practical applications, such as promoting children's and adolescents' PA in school PE and leisure time, PE teacher training, and the professional progress of existing PE teachers by providing a clearer understanding development of students' PA across the secondary school years. 


\section{REFERENCES}

Allison, K., Adlaf, E., Dwyer, J., Lysy, D., \& Irving, H. (2007). The decline in physical activity among adolescent students. A cross-national comparison. Canadian Journal of Public Health, 98, 97-100.

Arvidsson, D., Slinde, F., \& Hulthen, L. (2005). Physical activity questionnaire for adolescents validated against doubly labelled water. European Journal of Clinical Nutrition, 59, 376-383. doi:10.1038/sj.ejen. 1602084

Bates, H. (2006). Daily physical activity for children and youth: A review and synthesis of the literature. Alberta: Canadian Fitness and Lifestyle Research Institute.

Bergh, H., Grydeland, M., Bjelland, M., Lien, N., Andersen, L., Klepp, K., Anderssen, S., \& Ommundsen, Y. (2011). Personal and socialenvironmental correlates of objectively measured physical activity in Norwegian pre-adolescent children. Scandinavian Journal of Medicine and Science in Sports, 21, 315-324.

doi:10.1111/j.1600-0838.2011.01295.x

Biddle, S., Gorely, T., \& Stensel, D. (2004). Health-enhancing physical activity and sedentary behavior in children and adolescents. Journal of Sport Sciences, 22, 679-701. doi:10.1080/02640410410001712412

Brener, N., Billy, J., \& Grady, W. (2003). Assessment of factors affecting the validity of self-reported health-risk behavior among adolescents: Evidence from the scientific literature. Journal of Adolescent Health, 33, 436-457. doi:10.1016/S1054-139X(03)00052-1

Brodersen, N., Steptoe, A., Boniface, D., \& Wardle, J. (2007). Trends in physical activity and sedentary behaviour in adolescence: Ethnic and socioeconomic differences. British Journal of Sports and Medicine, 41, 140-144. doi:10.1136/bjsm.2006.031138

Corbin, C., Pangrazi, R., \& Le-Masurier, G. (2004). Physical activity for children: Current patterns and guidelines. The President's Council of Physical Fitness and Sports Research Digest, 52, 1-8.

Corder, K., Ekelund, U., Steele, R, Wareham, N., \& Brage, S. (2008). Assessment of physical activity in youth. Journal of Applied Physiology, 105, 977-987. doi:10.1152/japplphysiol.00094.2008

Currie, C., Samdal, O., Boyce, W., \& Smith, B. (2002). Health behavior in school-aged children: A WHO cross-national study. Research Protocol for the 2001-2002 Survey. Edinburgh: University of Edinburgh.

Dale, D., Welk, G., \& Mattews, C. (2002). Methods for assessing physical activity and challenges for research. In G. Welk (Ed.), Physical activity assessments for health-related research (pp. 19-34). Champaign: Human Kinetics.

de Vries, S., Bakker, I., Hopman-Rock, M., Hirasing, R., \& van Mechelen, W. (2006). Clinimetric review of motion sensors in children and adolescents. Journal of Clinical Epidemiology, 59, 670-680. doi:10.1016/j.jclinepi.2005.11.020

Duncan, M., Al-Nakeeb, Y., Nevill, A. \& Jones, M. (2004). Body image and physical activity in British secondary school children. European Physical Education Review, 10, 243-260. doi: $10.1177 / 1356336$ X04047125

Eston, R., Rowlands, A., \& Ingledew, D. (1998). Validity of heart rate, pedometry, and accelerometry for predicting the energy cost of children's activities. Journal of Applied Physiology, 84, 362-371.

Finnish Board of Education (2011). Follow-up evaluation of physical education learning outcomes. Helsinki: Follow-Up Reports of Education.

Gordon-Larsen, P., Nelson, M., \& Popkin, P. (2004). Longitudinal physical activity and sedentary behavior trends adolescence to adulthood. American Journal of Preventive Medicine, 27, 277-283. doi:10.1016/S0749-3797(04)00183-7

Harrell, J., McMurray, R., Baggett, C., Pennell, M., Pearce, P., \& Bangdiva S. (2005). Energy costs of physical activities in children and adolescents. Medicine and Science in Sports and Exercise, 37, 329336. doi:10.1249/01.MSS.0000153115.33762.3F

Keating, D. (2004). Cognitive and brain development. In R. Lerner, \& L. Steinberg (Eds.), Handbook of adolescent psychology (pp. 45-84). Hoboken, NJ: Wiley.

Marshall, S., \& Welk, G. (2008). Definitions and measurement. In A. Smith, \& S. Biddle (Eds.), Youth physical activity and sedentary behavior (pp. 3-29). Champaign: Human Kinetics.

McKenzie, T. (2002). The use of direct observation to assess physical activity. In G. Welk (Ed.), Physical activity assessments for healthrelated research (pp.179-195). Champaign: Human Kinetics.

Ministry of Social Affairs and Health (2007). Adolescents health and lifestyle survey. In M. Fogelholm, O. Paronen, \& M. Miettinen (Eds.) Physical activity - A possibility for welfare policy: The state and development of health-enhancing physical activity in Finland. Helsinki: Reports of the Ministry of Social Affairs and Health.

Moore, J., Maloney, H., \& Yin, Z. (2007). Differential relationship between subjectively and objectively measured physical activity and psychosocial correlates of physical activity in rural youth. Proceedings of the 135th APHA Annual Meeting and Exposition, Washington DC, 3-7 November 2007.

National Institute for Health and Welfare (2010). School Health Promotion Study 2010. URL. http://info.stakes.fi/kouluterveyskysely/FI/tulokset/index.htm

Prochaska, J., Sallis, J., \& Long, B. (2001). A physical activity screening measure for the use with adolescents in primary care. Archieves of Pediatrics and Adolescent Medicine, 155, 554-559.

Riddoch, C., Andersen, L., Wedderkopp, N., Harro, M., Klasson-Heggebø, L., Sardinha, L., Cooper, A., \& Ekelund, U. (2004). Physical activity levels and patterns of 9- and 15-yr-old European children. Medicine and Science in Sport and Exercise, 36, 86-92. doi:10.1249/01.MSS.0000106174.43932.92

Rodriguez, G., Beghin, L., Michaud, L., Moreno, L., Turck, D., \& Gottrand, F. (2002). Comparison of the TriTrac-R3D accelerometer and a self-report activity diary with heart rate monitoring for the assessment of energy expenditure in children. British Journal of Nutrition, 87, 623-631. doi:10.1079/BJN2002571

Rowlands, A. (2007). Accelerometer assessment of physical activity in children: An update. Pediatric Exercise Science, 19, 252-266.

Sallis, J., Cervero, R., Ascher, W., Henderson, K., Kraft, M., \& Kerr, J. (2006). An ecological approach to creating active living communities. Annual Review of Public Health, 27, 297-322. doi:10.1146/annurev.publhealth.27.021405.102100

Sherar, L., Esliger, D., Baxter-Jones, A., \& Trembley, M. (2007). Age and gender differences in youth physical activity: Does physical maturity matter? Medicine and Science in Sport and Exercise, 39, 830835. doi: $10.1249 / \mathrm{mss} .0 \mathrm{~b} 013 \mathrm{e} 3180335 \mathrm{c} 3 \mathrm{c}$

Shephard, R. (2003). Limits to the measurement of habitual physical activity by questionnaires. British Journal of Sport Medicine, 37, 197-206. doi:10.1136/bjsm.37.3.197

Shiely, F., \& MacDonncha, C. (2009). Meeting the international adolescent physical activity guidelines: A comparison of objectively measured and self-reported physical activity levels. Irish Medical Journal, 102, 15-19.

Sirard, J., \& Pate, R. (2001) Physical activity assessment in children and adolescents. Sports Medicine, 31, 439-454. doi:10.2165/00007256-200131060-00004

Slootmaker, S., Schuit, A., Chinapaw, M., Seidell, J., \& Mechelen, W. (2012). Disagreement in physical activity assessed by accelerometer and self-report in subgroups of age, gender, education and weight status. URL. http://www.ijbnpa.org

Tabachnick, B., \& Fidell, L. (2007). Using multivariate statistics. Boston, MA: Allyn and Bacon.

Thompson, A., Baxter-Jones, A., Mirwald, R., \& Bailey, D. (2003). Comparison of physical activity in male and female children: Does maturation matter? Medicine and Science in Sport and Exercise, 35, 1648-1690. doi:10.1249/01.MSS.0000089244.44914.1F

Troiano, R. (2009). Can there be a single best measure of reported physical activity? The American Journal of Clinical Nutrition, 89, 736-737. doi:10.3945/ajen.2008.27461

Troiano, R., Berrigan, D., Dodd, K., Mâsse, L., Tilert, T., \& McDowell, M. (2008). Physical activity in the United States measured by accelerometer. Medicine and Science in Sports and Exercise, 40, 181-188.

Trost, S. (2000). Objective measurement of physical activity in youth: Current issues, future directions. Exercise and Sport Science Reviews, 29, 32-36. doi:10.1097/00003677-200101000-00007

Trost, S., McIver, K., \& Pate, R. (2005). Conducting accelerometerbased activity assessments in field-based research. Medicine and Science in Sports and Exercise, 37, 531-543. doi:10.1249/01.mss.0000185657.86065.98 


\section{A. GRÅSTÉN ET AL.}

Trost, S., Pate, R., Freedson, P., Sallis, J., \& Taylor, W. (2000). Using objective physical activity measures with youth: How many days of monitoring are needed? Medicine and Science in Sports and Exercise, 32, 426-431. doi:10.1097/00005768-200002000-00025

Trost, S., Pate, R., Sallis, J., Freedson, P., Taylor, W., Dowda, M., \& Sirard, J. (2002). Age and gender differences in objectively measured physical activity in youth. Medicine and Science in Sports and Exercise, 34, 350-355. doi:10.1097/00005768-200202000-00025

Tudor-Locke, C., Williams, J., Reis, J., \& Pluto, D. (2002). Utility of pedometers for assessing physical activity. Convergent validity. Sports Medicine, 32, 795-808. doi:10.2165/00007256-200232120-00004

Virtanen, P. (2011). Measurement of children's physical activity. Development of Polar Active activity monitor. Proceedings from the International Congress on Enhancement of Physical Activity of Children and Youth, Vuokatti, 7-9 April 2011.

Welk, G., Wickel, E., Peterson, M., Heitzler, C., Fulton, J., \& Potter, L. (2007). Reliability and validity of questions on the youth media cam- paign longitudinal survey. Medicine and Science in Sports and Exercise, 39, 612-621. doi:10.1249/mss.0b013e3180305c59

World Health Organization (2004). Health behaviour in school-aged children: HBSC International report from the 2001/2002 survey. Geneva: World Health Organization.

World Health Organization (2008). Inequalities in young people's health. HBSC International report from the 2005/2006 survey. Geneva: World Health Organization.

World Health Organization (2012). Recommended levels of physical activity for children aged 5-17 years. URL.

http://www.who.int/dietphysicalactivity/ factsheet_young_people/en

Yang, K., \& Miller, G. (2008). Handbook of research methods in public administration. Boca Raton: Taylor \& Francis Group.

Yli-Piipari, S. (2011). The development of students' physical education motivation and physical activity-A 3.5-year longitudinal study across Grades 6 to 9. Ph.D. Thesis, Jyvaskyla: University of Jyvaskyla. 